\title{
Generation of a Homogeneous Glow Discharge: A Comparative Study between the Use of Fine Wire Mesh and Perforated Aluminium Electrodes
}

\author{
Zolkafle Buntat \\ Faculty of Electrical Engineering, Universiti Teknologi Malaysia \\ 81310 UTM Skudai, Johor, Malaysia \\ Ivor R.Smith \\ Department of Electronic and Electrical Engineering, Loughborough University \\ Loughborough, Leicestershire LE11 3TU, UK \\ Tel: 44-1509-227-005Ｅ-mail: i.r.smith@lboro.ac.uk \\ Noor. A. M. Razali \\ Faculty of Electrical Engineering, Universiti Teknologi Malaysia \\ 81310 UTM Skudai, Johor, Malaysia
}

Received: October 13, $2010 \quad$ Accepted: October 29, $2010 \quad$ doi:10.5539/apr.v3n1p15

\begin{abstract}
Ozone generation using both perforated-aluminium plate and fine-mesh stainless steel electrodes is studied, with the view to comparing the effectiveness of the two technologies in improving the stability of the glow discharge that they produce at atmospheric pressure. Electric field computations using simulation software (Ansoft-Maxwell 2D) indicate that the wire mesh generates the higher electric field strength, in contrast to an initial assumption that the perforated aluminium would be better because of its sharp-edged holes. Experimental work confirms however that the discharge configuration with perforated aluminium electrodes produces a better glow discharge stability at atmospheric pressure, showing that the electric field strength does not influence the stability of the glow discharge, as was also noted by previous authors. The perforated-aluminium plate discharge system may therefore be an effective means of improving the ozone generation and removing the pollutant gases.
\end{abstract}

Keywords: Glow discharge, Ozone generation, Fine wire mesh, Perforated electrode, Plasma reactor

\section{Introduction}

In general, a glow discharge is only stable at pressures of less than a few mbars [S Okazaki, 1993; J Tepper, 2002]. At atmospheric pressure the discharge is normally unstable, and in most cases it tends to change to a filamentary discharge, [F Massines, 1998; J Tepper, 2000; S Kanazawa., 1988], depending on the feed gas, the material of the dielectric barrier, the structure of the discharge electrode, the frequency of the pulsed supply, the gap spacing and the humidity of the gas.

Several authors claim [S Kanazawa., 1988; T Yokoyama, 1990; J E Harry, 1999] however to have obtained a stable glow discharge at atmospheric pressure depending on three simple requirements (i) a source frequency above $1 \mathrm{kHz}$, (ii) the insertion of a dielectric plate (or plates) between the two metal electrodes and (iii) the use of helium as a dilution gas. The ability of helium to produce a stable and homogeneous glow discharge at atmospheric pressure is related to its low breakdown stress [Y P Raizer, 1991]. Since this is only about 300 $\mathrm{V} / \mathrm{mm}$, some ten times lower than that of air, it is relatively easy to produce the small avalanches that are required [Y Sawada, 1995]. Despite its attractive features, it is however impractical to use helium in ozone generation, due to its high cost and the low efficiency of the process. 
Another important result relating to the stabilization of an atmospheric pressure glow discharge (APGD) is its appearance in air, argon and oxygen when using a $50 \mathrm{~Hz}$ source and a fine wire mesh as the discharge electrodes [S Okazaki, 1993]. These initial experiments have since been confirmed [J Tepper, 2000; T Yokoyama, 1990], and it has also been established that fine mesh electrodes produce a more stable glow than do coarse mesh electrodes [J Tepper, 2002]. Since ozone is commonly generated in air or in oxygen, the production of an APGD in air is potentially important, and forms therefore the focus of the present investigation.

In the paper, perforated aluminum sheet electrodes are introduced into a reaction chamber for comparison with the well established fine stainless steel wire mesh. A perforated sheet consisting of a series-parallel arrangement of small sharp - edged holes (Fig 1(a)), is expected to produce a higher local electric field strength than a fine wire mesh (Figs. 1b)), which may be sufficient to cause ionization of the gas in the vicinity of the sharp edges. This will, in turn produce more micro-discharges near the electrodes and, further, will provide a discharge that fills the entire volume of the discharge chamber. If a dielectric barrier is present, the increased field strength will lead to an increased number of micro-discharges of nanosecond duration [M Haacke, 2000], each consisting of a thin almost cylindrical channel, with an intense region at the metal electrode and spreading into a glow discharge on the dielectric surface.

Additionally, a greater perforation density with small diameter holes may produce the same effect as a fine wire mesh, at both low and high voltages. However, with a higher concentration of holes and sharp edges, the smaller diameters are expected to provide a higher and more uniform electric field for charging the dielectric barrier surface than does the wire mesh. It is also expected that the physical structure of the perforated metal, such as the shape and diameter of the holes and the metal thickness, will all influence the breakdown mechanism and the discharge stability. This certainly warrants further investigation and will form the topic of future research.

\section{Electric field simulation}

Before undertaking a comparative study between wire mesh and perforated metal electrodes it was necessary to estimate the electric field strength produced by both structures, in order to identify the effect of the field strength on the discharge stability. It is reported that the ionization rate in the discharge chamber depends on the local field strength [T.C Montie, 2000], with a higher rate produced by an increased field strength. A higher local field, as produced by the sharp edges of the perforated metal, is also believed to effect the glow discharge stability.

Electric field computations for both structures were carried out using simulation software (Ansoft-Maxwell 2D), a complex code able to simulate electromagnetic fields under static conditions and at high frequencies. For the present purpose only the electrostatic field module was used. In the first step of this, a grid is created that describes the geometry in which the electric field is applied and the potential difference and the electrical characteristics (dielectric constant) of the medium are then defined. Based on the discrete grid, the Maxwell equations are solved at each point within the software and the solution is displayed in graphical form. The resulting electric field distributions with both perforated aluminium sheet and stainless steel wire mesh electrodes are presented in Fig. 2.

Table 1 presents simulated values of the electric field strength produced by different sized steel wire mesh. At any given input voltage an increase in the diameter of the wire (reducing the number of wires per $\mathrm{cm}^{2}$ ) results in a reduction in the electric field strength. For an input voltage of $3 \mathrm{kV}$ an electric field strength of $31.49 \mathrm{kV} / \mathrm{mm}$ is achieved with the smallest wire, corresponding to an average electron energy of $21.9 \mathrm{eV}$.

Table 2 presents simulated values of the electric field strength produced by perforated aluminium with different hole diameters. At any given input voltage an increase in the hole diameter leads to a decrease in the electric field strength. For an input voltage of $3 \mathrm{kV}$, an electric field strength of $11.49 \mathrm{kV} / \mathrm{mm}$ is achieved with the smallest hole, corresponding to an average electron energy of $9.9 \mathrm{eV}$.

It was concluded from the results above that wire mesh generates the higher electric field strength, in contrast to an initial assumption that the sharp edges of the perforated aluminium would lead to the higher value. Further verification of the effect of the different electrode structures needs therefore to be obtained experimentally.

\section{Experimental set-up and procedure}

Fig. 3 shows the experimental arrangement used to compare the electrode structures, using either a fine steel wire mesh of 325 meshes per inch and $0.035 \mathrm{~mm}$ wire diameter (\#352, 0.035).or a plane-to-plane configuration of perforated aluminium sheet having $1.2 \mathrm{~mm}$ diameter holes and $23 \%$ open area. A double-barrier arrangement was adopted, with an electrode (20 $\mathrm{mm}$ in length and $20 \mathrm{~mm}$ in width) located between the aluminium foil and the dielectric barrier. 
The aluminium foil serves as a high-voltage electrode on one side of the reaction chamber and as the ground electrode on the other side. Mica sheet $130 \mu \mathrm{m}$ thick was used as the dielectric barrier, to permit the charge build-up that maintains the plasma from one half-cycle of the supply to the next [Y Sawada, 1995; M Haacke, 2000].

The gap spacing and the air flow rate were kept constant at $1 \mathrm{~mm}$ and $11 / \mathrm{min}$ respectively, and a voltage between 1 and $20 \mathrm{kV}$ at a frequency of $50 \mathrm{~Hz}$ was supplied to the APGD reactor. Dry air with a relative humidity below $20 \%$ was used as the input gas. A $240 \mathrm{~V} / 20,000 \mathrm{~V}, 5 \mathrm{~mA}, 50 \mathrm{~Hz}$ high voltage step-up transformer provided the supply to the electrodes, with the primary voltage controlled to between 0 and $240 \mathrm{~V}$ by a variable autotransformer.

The voltage supplied to the reactor was measured by means of a low-inductance voltage divider and a charge signal was obtained from the voltage across a $0.22 \mu \mathrm{F}$ capacitor connected in series to ground. The output signals were recorded using a digital storage oscilloscope (LeCroy 9344) having a bandwidth of $500 \mathrm{MHz}$ and a sample rate of $1 \mathrm{GS} / \mathrm{s}$.

\section{Experimental investigation}

Since visual observations are clearly inadequate for comparing the stability of the different discharges, two familiar discharge behaviour techniques were adopted. These require observation of either the voltage-charge Lissajous figures or the characteristics of the discharge current. [J Tepper, 2000; S Kanazawa., 1988; T Yokoyama, 1990]

The discharge behaviour was observed for $\# 325,0.035 \mathrm{~mm}$ wire mesh and perforated aluminium sheet with 1.2 $\mathrm{mm}$ diameter holes, at supply voltages to the reactor of $1.2,1.4,1.6$ and $1.8 \mathrm{kV}$ for a $1.5 \mathrm{~mm}$ gap spacing. The gas flow rate was $1 \mathrm{l} / \mathrm{min}$ and the gas pressures was 1 bar.

\subsection{Voltage-charge Lissajous figure}

The voltage-charge Lissajous figures [S Okazaki, 1993] were obtained using the circuit of Fig. 4, with the attenuated high reactor voltage across the resistor R2 and that across the $0.22 \mu \mathrm{F}$ capacitor fed to the orthogonal pairs of plates of the recording oscilloscope. The appearance of two straight lines, as the top and bottom sides of a parallelogram, is an indication of the existence of a glow discharge. The presence of a staircase-like waveform, with or without continuous connecting lines, is an indication of the existence of a filamentary discharge and a mixed glow-filamentary discharge respectively, [J Tepper, 2000]. The Lissajous figures obtained are shown in Figs.5

Fig 5 shows the effect of different applied voltages when using wire mesh electrodes. The presence of only two straight lines in Fig. 5(a) is evidence that at a reactor voltage of $1.2 \mathrm{kV}$ only a glow discharge was present. Increasing the voltage to $1.4 \mathrm{kV}$ and then to $1.6 \mathrm{kV}$ produced the mixed glow-filamentary discharge, indicated in Figs 5(b) and 5(c) respectively by the staircase-like regions of these waveforms. Finally, the presence of the continuous connecting lines in the staircase-like regions of Fig $5(\mathrm{~d})$ is evidence that a complete transition to a filamentary discharge has taken place at a voltage of $1.8 \mathrm{kV}$ (and above).

Fig 6 shows Lissajous figures obtained at different values of applied voltage when using perforated aluminium $(1.2 \mathrm{~mm}, 23 \%$ open area) electrodes. The two lines of Fig. 6(a) demonstrate that at $1.2 \mathrm{kV}$ a pure glow discharge is produced. Fig $6(\mathrm{~b})$ shows that at a voltage of $1.4 \mathrm{kV}$, there is a slight change toward a mixed glow-filamentary discharge, and the extended staircase-like region in Fig 6(c) shows that this change is strengthened at $1.6 \mathrm{kV}$. Even at $1.8 \mathrm{kV}$, Fig 6(d), a purely filamentary discharge is not obtained, unlike the results of Fig 5(d). Raising the voltage further to $2.0 \mathrm{kV}$, finally resulted in the discharge becoming entirely filamentary. However, for comparative purposes, all the results for the gap spacing of $1.5 \mathrm{~mm}$ in this study are shown up to a maximum of $1.8 \mathrm{kV}$.

\subsection{Characteristic of applied voltage and discharge current}

Observations of the voltage and discharge current waveforms were obtained using the circuit of Fig. 7. A glow discharge is characterized by the appearance of a single current pulse in each half period of the reactor supply voltage, whereas the existence of a filamentary discharge is indicated by the presence of several current pulses in each half period [J Tepper, 2000]. No specific characteristics have been identified previously for a mixed glow-filamentary discharge, but it was noted in the present study that when a Lissajous figure contained staircase regions without continuous connecting lines, several current pulses in one half period of the input voltage but a maximum of only two in the other half cycle. This feature was therefore adopted as an indicator of the presence of a mixed glow-filamentary discharge. 
Typical oscillograms of the applied voltage and the discharge current over an complete voltage cycle for the different electrodes investigated are shown in Figs. 8 and 9..

Fig. 8 shows results obtained for the APGD in air when using wire mesh electrodes. (325 meshes per in, 0.035 $\mathrm{mm}$ electrodes). At $1.2 \mathrm{kV}$, the discharge current is clearly characterized by one pulse per half cycle, indicating the existence of a pure glow discharge. Increasing the voltage to $1.4 \mathrm{kV}$ and then to $1.6 \mathrm{kV}$ generates a mixed glow-filamentary discharge as evident in Figs. 8(b) and 8(c) from the presence of several pulses in the positive half cycle, but only a single pulse in the negative half cycle. Increasing the input voltage further to $1.8 \mathrm{kV}$ changes the glow-filamentary discharge to a filamentary discharge alone, as shown in Fig. 8(d) by the existence of several pulses in both the positive and negative half cycles, although with very small amplitudes.

Fig.9 shows the voltage and discharge current waveform of the APGD produced by perforated aluminium (1.2 $\mathrm{mm}$ diameter, $23 \%$ open area) electrodes. Figs. 9(a) and (b) show that at both $1.2 \mathrm{kV}$ and $1.4 \mathrm{kV}$ the discharge current waveform exhibits a single pulse per half cycle and only a glow discharge is produced. Fig. 9(c) shows that when the input voltage is increased to $1.6 \mathrm{kV}$ the discharge current waveform begins to contain several pulses in one half cycle of the input voltage and a maximum of two current pulses in the other half cycle and when the input voltage is further increased to $1.8 \mathrm{kV}$ this is evident in both the positive and negative current pulses seen in Fig. 9(d). A mixed glow-filamentary discharge is therefore produced at both input voltages without changing to a filamentary discharge, confirming the findings from the Lissajous figure.

In order to investigate further the effectiveness of perforated aluminium and fine wire mesh electrodes, a comparative study between the APGD produced by the two arrangements was made with an increased gap spacing of $3 \mathrm{~mm}$ using both Lissajous figures as shown in Fig. 10 and Fig. 11 respectively and the discharge current waveforms as shown in Fig. 12 and Fig. 13 respectively. As a consequence of the increased spacing, experiments were performed at $2.8 \mathrm{kV}, 3.2 \mathrm{kV}, 3.6 \mathrm{kV}$ and $4.0 \mathrm{kV}$.

It was found that a glow discharge was produced by the wire mesh electrodes at $2.8 \mathrm{kV}$, a mixed glow-filamentary discharge at $3.2 \mathrm{kV}$ and $3.6 \mathrm{kV}$ and finally a filamentary discharge only at $4.0 \mathrm{kV}$. The form of the results evident on the oscilloscope for both techniques were similar to those presented earlier in Figs 5 and 6 for the $1.5 \mathrm{~mm}$ gap The results obtained when the mesh electrodes were replaced by perforated electrodes were used similar to those with the $1.5 \mathrm{~mm}$ gap, with the number of current pulses in alternate half cycles of the supply voltage again demonstrating a progressive change from a glow to a filamentary discharge as the voltage was raised from $2.0 \mathrm{kV}$ to $4.0 \mathrm{kV}$.

\section{Discussion of results}

It has been found that aluminium sheet electrodes perforated with small holes and a gap spacings of 1.5 and 3.0 $\mathrm{mm}$ can generate a homogeneous glow discharge in air at a frequency as low as $50 \mathrm{~Hz}$ This is evident by comparing the discharge behaviour of the two configurations using either the Lissajous figures of Figs 5 and 6 or the voltage and current discharge waveforms of Figs 8 and 9, or corresponding results (not presented here) for the $3.0 \mathrm{~mm}$ gap.

The $3.0 \mathrm{~mm}$ gap spacing between the dielectric plates was about the maximum at which a stable glow discharge could be produced, and beyond this the glow was unstable and as found in previous work [S Okazaki, 1993; J Tepper, 2002; S Kanazawa., 1988] tended to develop into a filamentary discharge. Similarly, the stability of the discharge depends on the voltage applied the reactor, and the maximum voltage at which a stable discharge could be maintained was $1.6 \mathrm{kV}$ and $3.6 \mathrm{kV}$, for spacing of the wire mesh electrodes of $1.5 \mathrm{~mm}$ and $3.0 \mathrm{~mm}$ respectively. Whereas, for perforated aluminium, the stability of the glow discharge can be achieved at a maximum applied input voltage of $1.8 \mathrm{kV}$ and $4.0 \mathrm{kV}$ at the gap spacings of $15 \mathrm{~mm}$ and $3.0 \mathrm{~mm}$ respectively, which is slightly higher than the wire mesh.

The reason why the glow discharge produced by the configuration with perforated aluminium has a better stability than the wire mesh is unclear, since the simulation results for the electric field strength obtained between the two materials showed that the wire mesh configuration produced a higher electric field strength than did the perforated aluminium. This indicates that the electric field strength does not influence the stability of the glow discharge, and is in general agreement with the finding in previous work [J Tepper, 2000].

However, it may be the shape and size of the holes, as well as the material used, which helps to distribute uniformly the electric field strength throughout the electrode surface, leading to a more uniform and stable glow discharge on the dielectric surface. The preliminary experimental results indicated that, with small diameter holes of perforated aluminium, the glow discharge produced is more stable than with bigger holes suggesting that the hole shape and diameter both have an influence on the glow discharge stability. It is expected therefore 
that with smaller diameter perforated holes of different shape (i.e of vee or cone form), a better stability of the glow discharge can be achieved.

The effect of the material is also evident, when with the use of perforated aluminium a more stable glow discharge is produced than with perforated zinc or even the steel wire mesh. It can be expected that a better stability of glow discharge can be obtained with the use of perforated copper. This is because copper has a better oxidation process and produces a higher stress at the electrode surface, which in turn will produce more micro-discharges around the electrode. This assumption provides the opportunity for future research.

\section{Conclusions}

The above finding can be summarised as follows:

i.) A homogeneous glow discharge can be produced using a perforated metal electrode configuration instead of the well established fine steel wire mesh.

ii.) Perforated aluminium with a small hole diameter can be used to generate a stable atmospheric pressure glow discharge in air at a frequency as low as $50 \mathrm{~Hz}$.

iii.) The atmospheric pressure glow discharge generated by the perforated aluminium attached behind the dielectric barrier produced a better stability than when attached by the wire mesh.

iv.) The electric field strength does not influence the stability of the glow discharge, and this is in general agreement with the findings of previous work.

v.) The stability of the glow discharge depends on the gap spacing and the applied input voltage, which is in general agreement with previous work.

vi.) The stability of the glow discharge depends on the hole diameter of perforated sheet and the materials used. This was noted in preliminary experiments and further investigation.

vii.) Perforated copper with small diameter holes is expected to produce a better stability than aluminium, since it gives better oxidation process and produce more micro-discharges around the electrode.

With the above findings, the glow discharge produced by the configuration with perforated aluminium attached behind the dielectric barrier may be useful for improving the ozone generation and removing the pollutant gases.

\section{Acknowledgement}

Dr. Z Buntat and Miss N.A.M Razali are indebted to the Ministry of Higher Education of Malaysia, Universiti Teknologi Malaysia and the University Malaysia Perlis for financial support received during the course of this investigations.

\section{References}

Buntat Z, Harry J.E and Smith I.R. (2002). Atmospheric pressure glow discharge and pulsed streamer discharge for ozone generation. European Pulsed Power Symposium, Saint Louis, France.

Haacke M and Pietsch G.J. (2000). Some features of dielectric barrier discharge. Proc. $13^{\text {th }}$ Int. Conf. Gas Discharges \& Their Applications, Glasgow, pp 267-270.

Harry J E and Yahya A A. (1999). Factors affecting the glow-to-arc transition at the cathode of an electric discharge at atmospheric pressure. Int. J. Electronics, Vol.86, No.6, pp. 755-762.

Kanazawa S., Kogoma M, Moriwaki T and Okazaki S. (1988). Stable glow plasma at atmospheric pressure. J. Phys D: Appl. Phys., Vol. 21, pp. 838-840.

Kogoma M and Okazaki S. (1994). Raising of ozone formation efficiency in a homogeneous glow discharge plasma at atmospheric pressure. J. Phys., D 27, pp. 1985-1987.

Massines F, Rabehi A, Decomps Ph, Gadri R B, Segur P, and Mayoux C. (1998). Mechanisms of a glow discharge at atmospheric pressure controlled by dielectric barrier. Journal of Applied Physics, Vol. 83, No. 6, pp. 2950-2957.

Montie T.C, Kelly-Wintenberg K., Roth J.R. (2000). An overview of research using a one atmosphere uniform glow discharge plasma (OAUGDP) for sterilization of surfaces and materials. IEEE Trans. Plasma Science, Vol.28, No.1.

Okazaki S, Kogoma M, Uehara M and Kimura Y. (1993). Appearance of stable glow discharge in air, argon, oxygen and nitrogen at atmospheric pressure using $50 \mathrm{~Hz}$ source. J.Phys. D: Appl. Phys., Vol. 26, pp. 889-892. 
Park J, Henins I, Hermann H. W, Selwyn G. S, Jeong J. Y, Hicks R. Shim F, D, and Chang C S. (2000). An atmospheric pressure plasma source. Appl. Phys. Lett., Vol.76, No. 3, pp.288-290.

Raizer Y P. (1991). Gas Discharge Physics (Berlin: Springer).

Sawada Y, Ogawa S, and Kogoma M. (1995). Synthesis of plasma-polymerized tetraethoxysilane and hexamethyldisiloxane films prepared by atmospheric pressure glow discharge. J. Phys. D., Appl. Phys., Vol. 28, pp. 1661-1669.

Spence P and Roth J. R. (1994). Electrical and plasma characteristics of a one atmosphere glow discharge plasma reactor. IEEE Conference on Plasma Science, Santa Fe, NM, June 6-8.

Tepper J and Lindmayer M. (2000). Investigations on two different kinds of homogeneous barrier discharges at atmospheric pressure, Proc. of Int. Symp. on High Pressure. Low Temperature Plasma Chemistry, Hakone VII, Greifwald, Germany, pp. 38-43.

Tepper J, Li P and Lindmayer M. (2002). Effects of interface between dielectric barrier and electrode on homogeneous barrier discharges at atmospheric pressure. XIV International Conference on Gas Discharges and their Application, Liverpool, United Kingdom, pp. 1-4.

Trunec D, Brablec A and Buchta J. (2000). Efficiency of ozone production in atmospheric pressure glow and silent discharges", Proc. of Int. Symp. On High Pressure. Low Temperature Plasma Chemistry, Hakone VII, Greifwald, Germany, pp. 313-317.

Yokoyama T, Kogoma M, Moriwaki T, and Okazaki S. (1990). The mechanism of the stabilization of glow plasma at atmospheric pressure. J. Phys. D: Appl. Phys., Vol. 23, pp. 1125-1128.

Table 1. Electric field strength at different input voltages and wire mesh sizes

\begin{tabular}{|c|c|c|c|c|}
\hline $\begin{array}{c}\text { Irqut } \\
\text { Voltage } \\
(\mathrm{k} T)\end{array}$ & 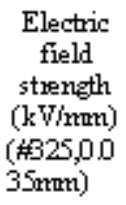 & 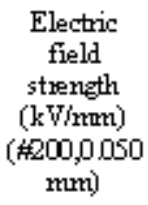 & 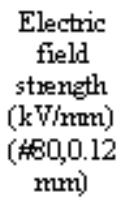 & 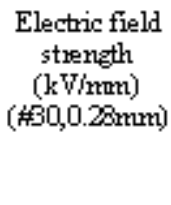 \\
\hline 3 & 31.49 & 278 & 1830 & 14.80 \\
\hline 4 & 41.95 & 36.50 & 24.40 & 19.85 \\
\hline 5 & 52.44 & 45.60 & 32.41 & 24.81 \\
\hline 6 & 6293 & 54.75 & 388 & 2977 \\
\hline 7 & 73.42 & 63.88 & 45.37 & 34.73 \\
\hline
\end{tabular}

Table 2. Electric field strength at different input voltages and hole diameter of perforated aluminium sheet

\begin{tabular}{|c|c|c|c|c|}
\hline $\begin{array}{c}\text { Irquat } \\
\text { Toltage } \\
(\mathrm{kT})\end{array}$ & $\begin{array}{c}\text { Electric } \\
\text { field } \\
\text { strength } \\
\text { (kThum) } \\
\text { (bole = } \\
O 12 \text { num } \\
\text { pitch = } \\
1.7 \text { rumj }\end{array}$ & 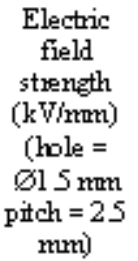 & 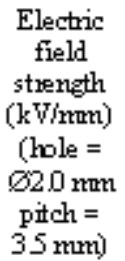 & $\begin{array}{c}\text { Electric field } \\
\text { strength } \\
\text { (kWinmu) } \\
\text { (hole = } 3.0 \mathrm{rtm} \\
\text { pitch }=5.0 \mathrm{rmm})\end{array}$ \\
\hline 3 & 11.49 & 11.28 & 11.18 & 11.00 \\
\hline 4 & 1531 & 15.04 & 1491 & 14.71 \\
\hline 5 & 19.14 & 1879 & 1864 & 1838 \\
\hline 6 & 2297 & 22.55 & 22.37 & 22.05 \\
\hline 7 & 2600 & 26.31 & 2600 & 25.73 \\
\hline
\end{tabular}




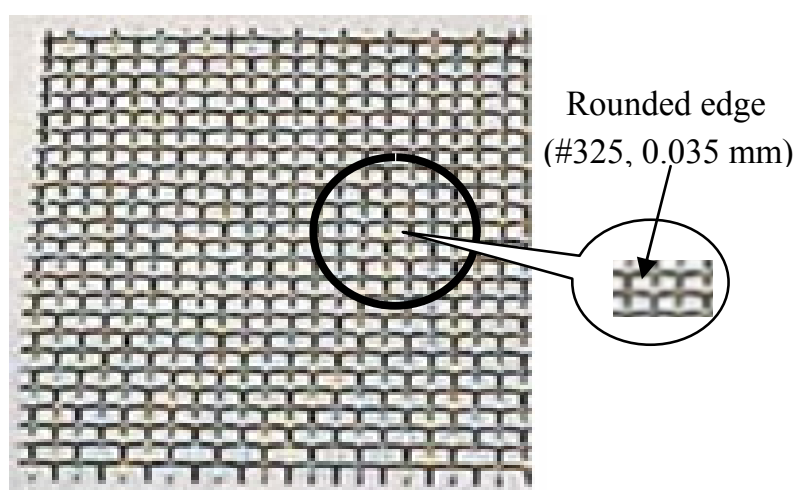

a)

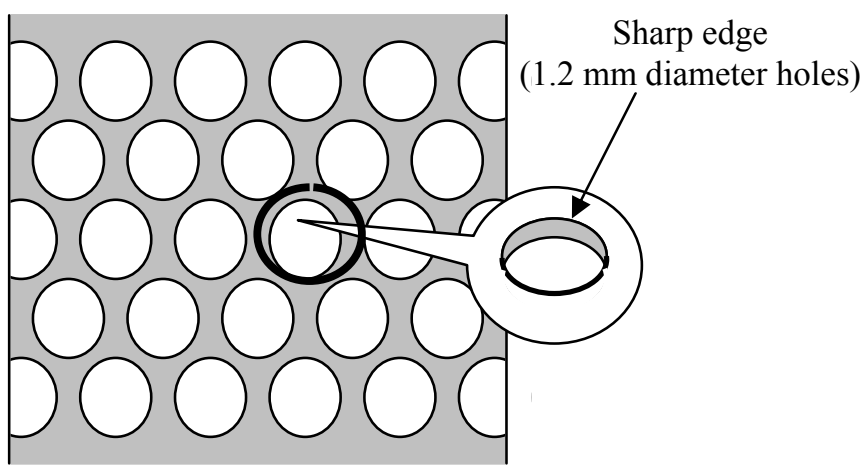

b)

Figure 1. Arrangement of electrodes a) fine steel wire mesh. b) perforated metal sheet 


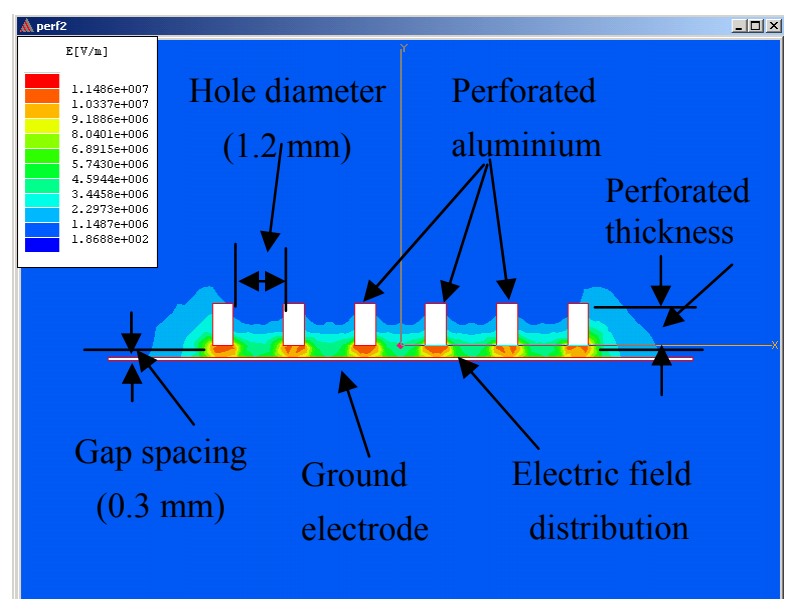

b)

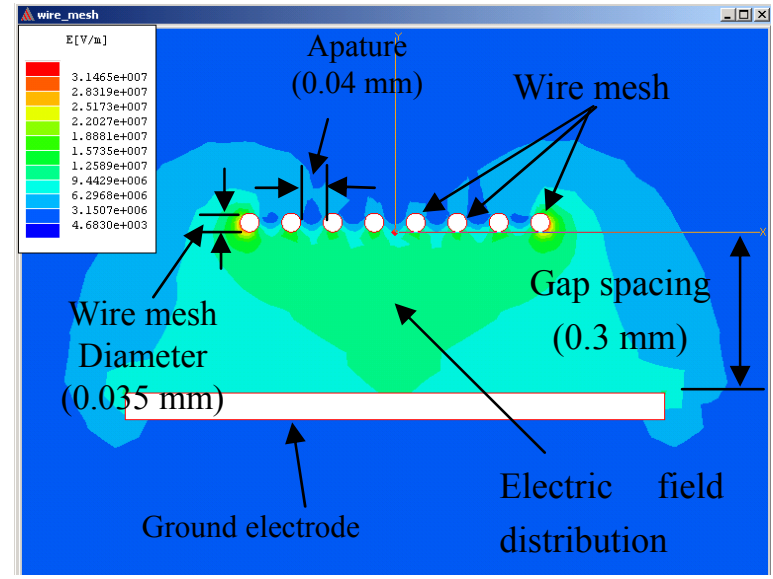

a)

Figure 2. Ansoft-Maxwell 2D simulation of electric field strength and distribution a) stainless steel wire mesh b) perforated aluminium electrodes

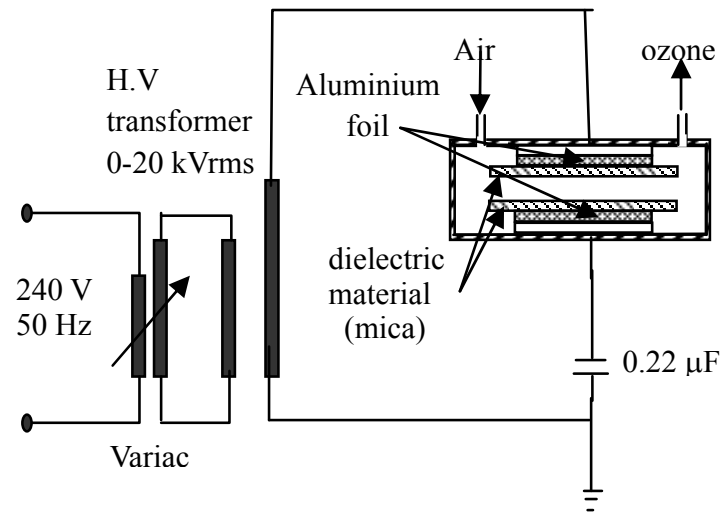

Figure 3. Experimental arrangement for comparing the glow discharge stability 


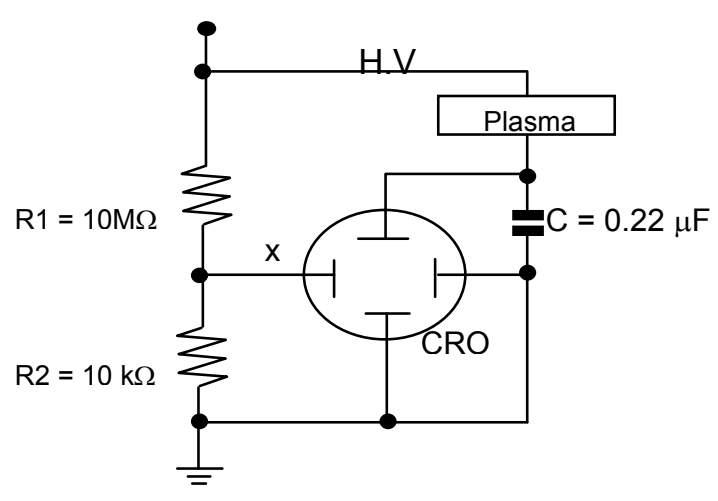

Figure 4. Circuit to provide Lissajous voltage-charge characteristics [J Tepper, 2000]

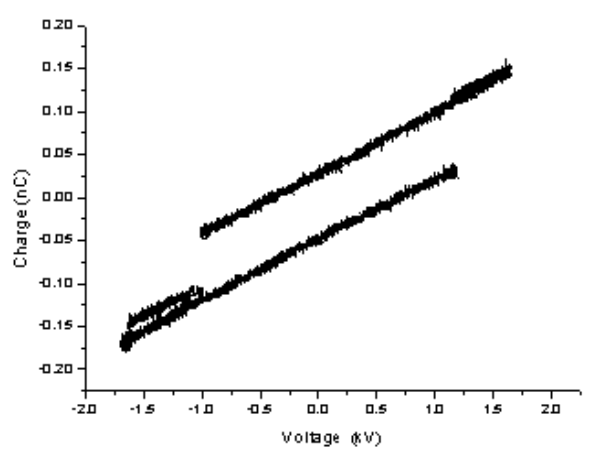

(a)

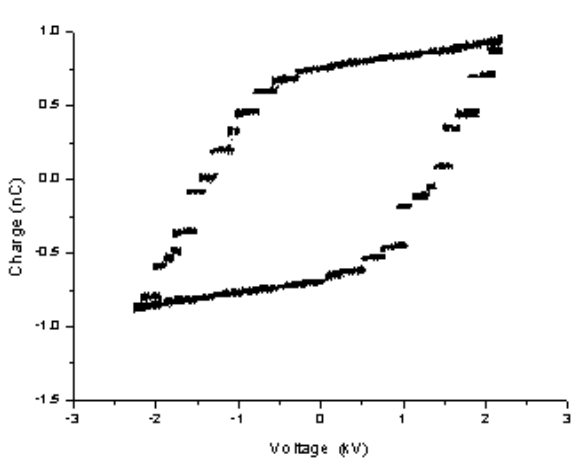

(c)

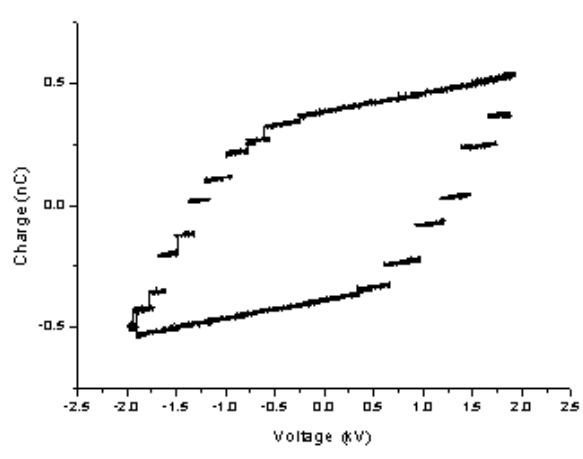

(b)

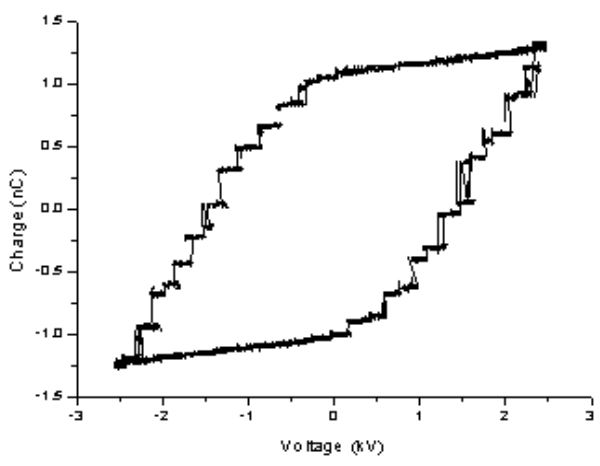

(d)

Figure 5. Voltage-charge Lissajous figure for fine steel wire mesh at (a) $1.2 \mathrm{kV}$, (b) $1.4 \mathrm{kV}$, (c) $1.6 \mathrm{kV}$, (d) 1.8 $\mathrm{kV}$ 


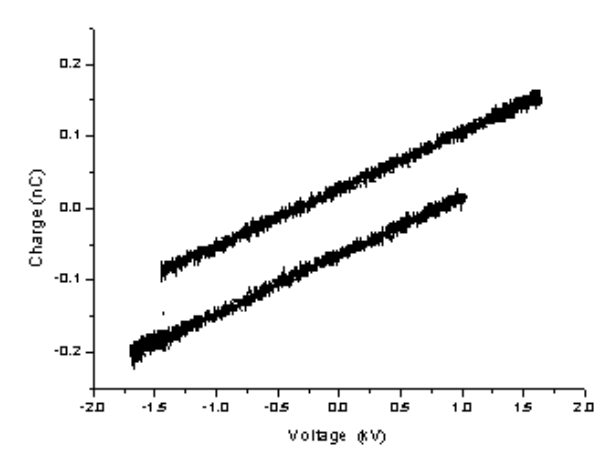

(a)

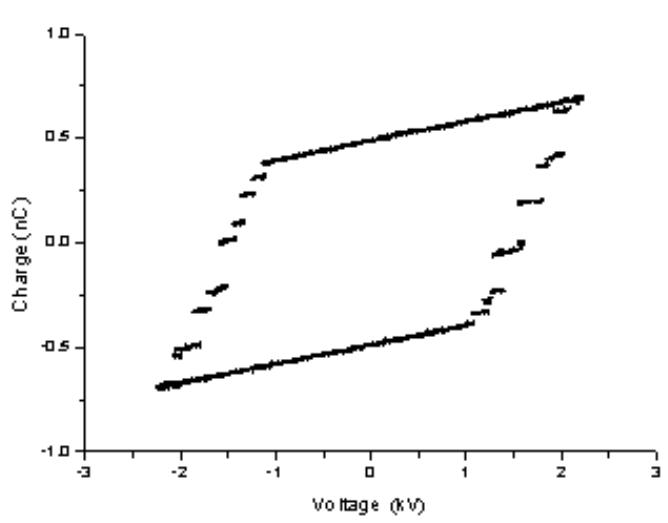

(c)

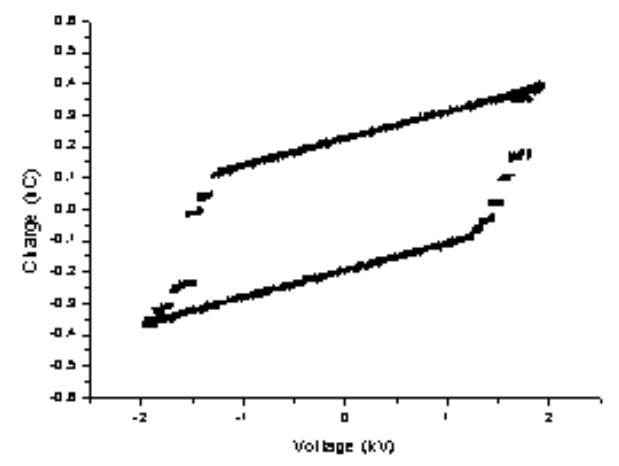

(b)

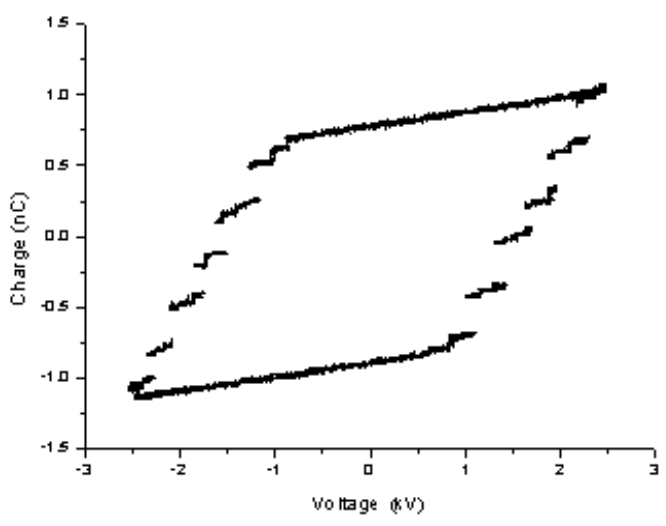

(d)

Figure 6. Voltage-charge Lissajous figure for perforated aluminium (1.2 mm diameter, $23 \%$ open area) at (a) 1.2 $\mathrm{kV}$, (b) $1.4 \mathrm{kV}$, (c) $1.6 \mathrm{kV}$, (d) $1.8 \mathrm{kV}$

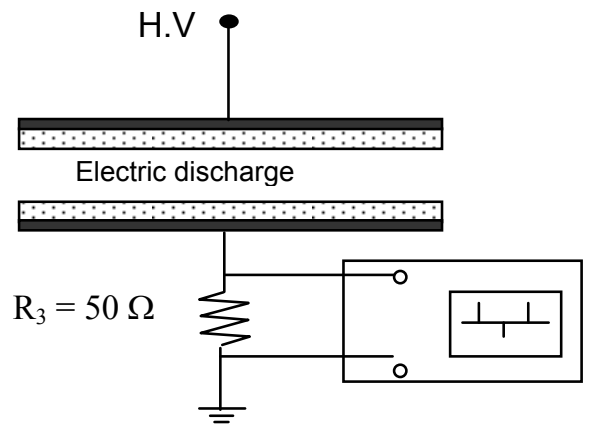

Figure 7. Circuit to record discharge current waveform 


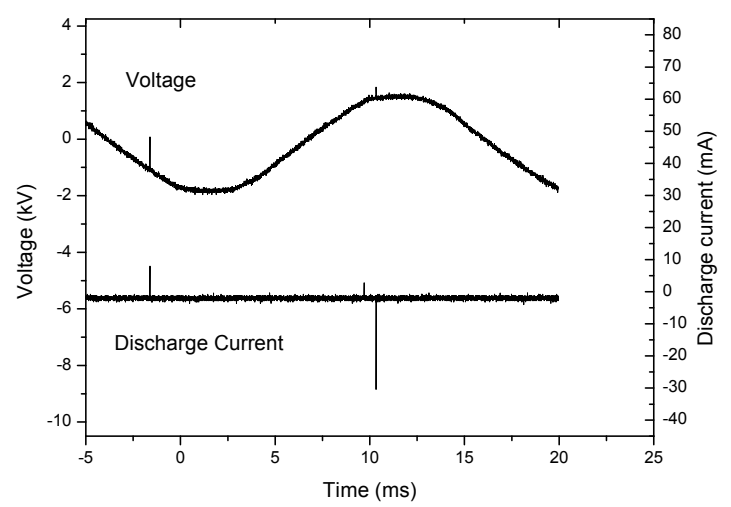

(a)

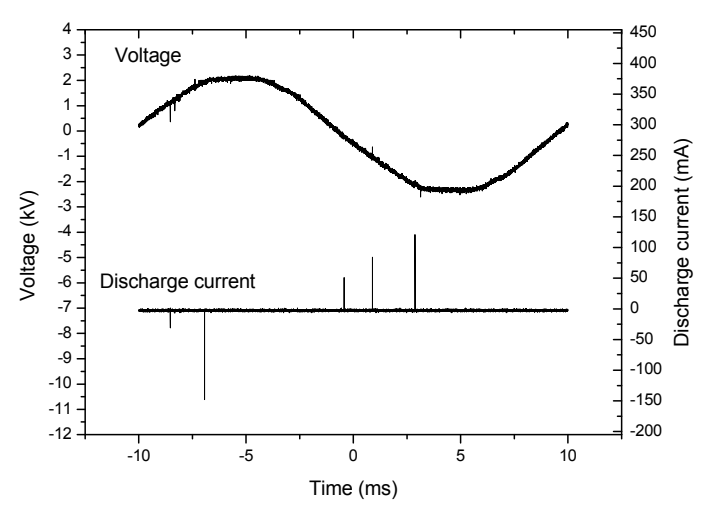

(c)

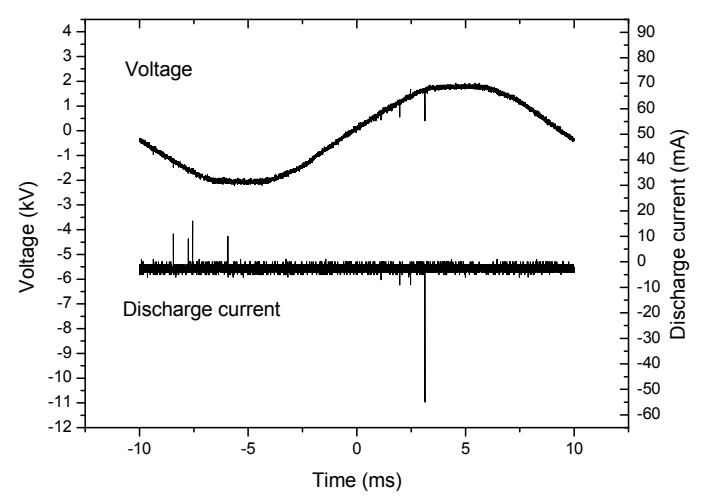

(b)

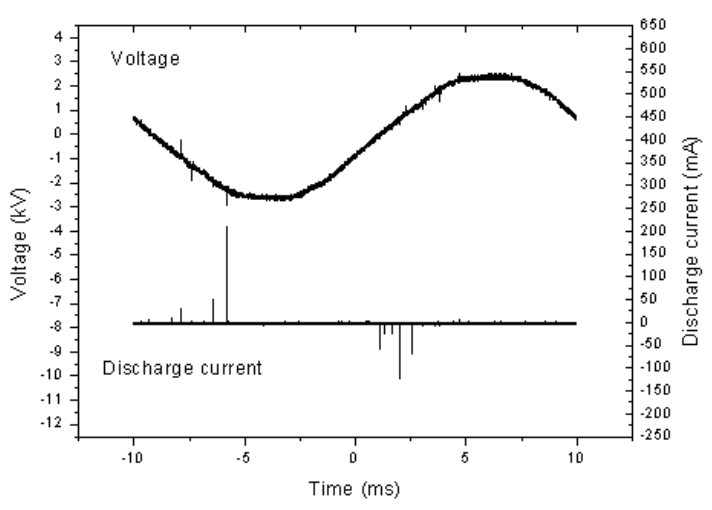

(d)

Figure 8. Voltage and discharge current waveform for steel wire mesh (\#325, $0.035 \mathrm{~mm}$ ) at (a) $1.2 \mathrm{kV}$, (b), 1.4 $\mathrm{kV}$, (c) $1.6 \mathrm{kV}$, (d) $1.8 \mathrm{kV}$

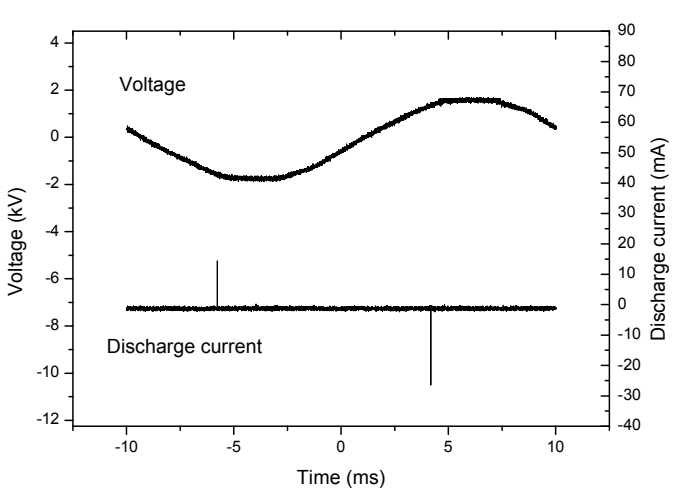

(a)

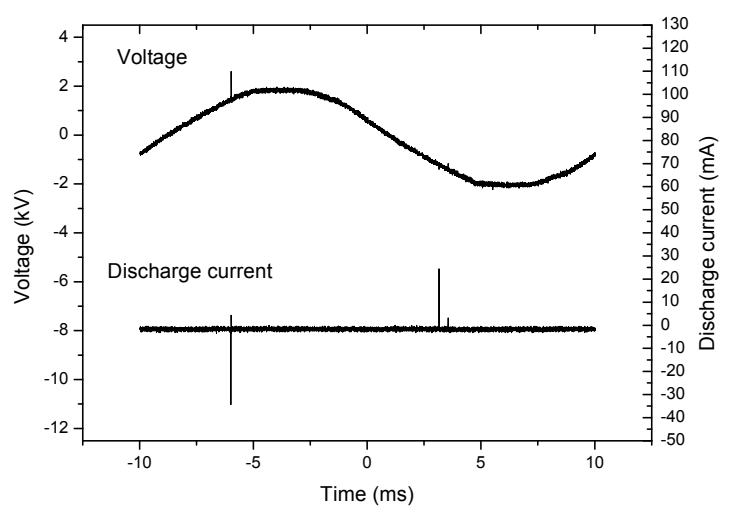

(b) 


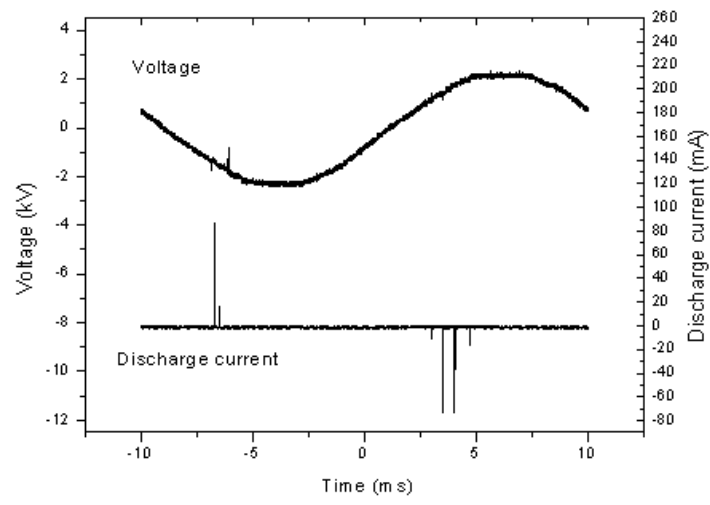

(c)

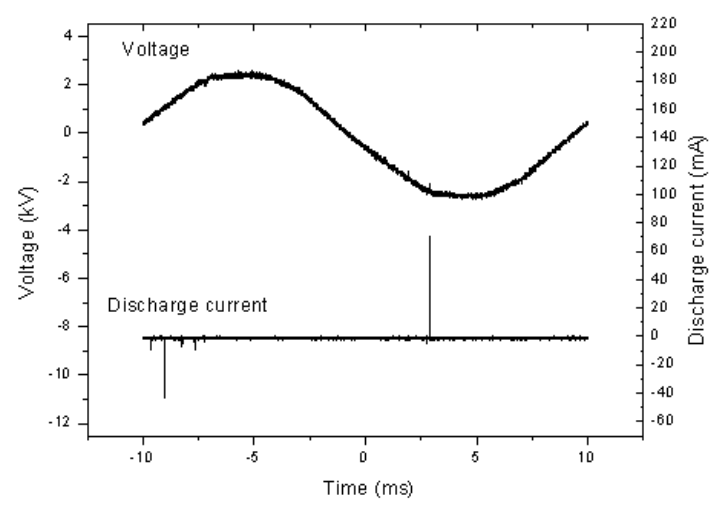

(d)

Figure 9. Voltage and discharge current waveform for perforated aluminium (1.2 $\mathrm{mm}$ diameter, $23 \%$ open area) at (a) $1.2 \mathrm{kV}$, (b), $1.4 \mathrm{kV}$, (c) $1.6 \mathrm{kV}$, (d) $1.8 \mathrm{kV}$

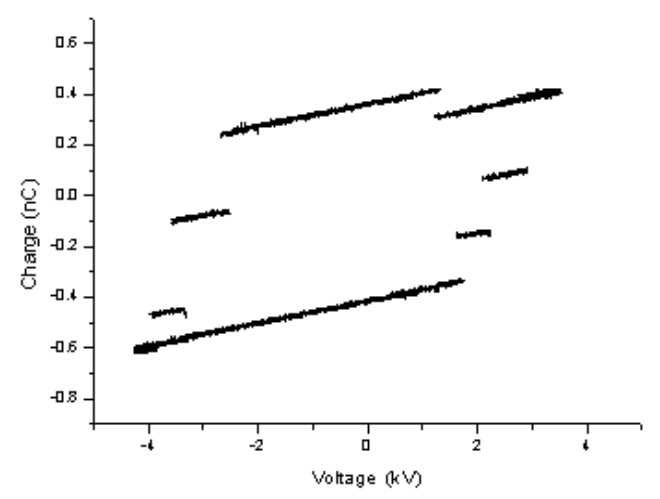

(a)

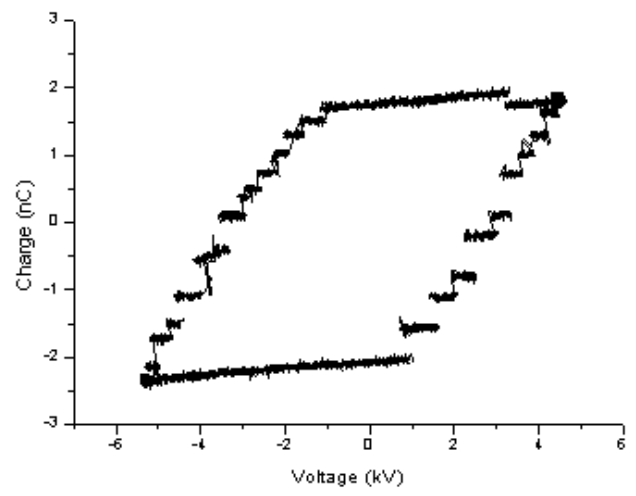

(c)

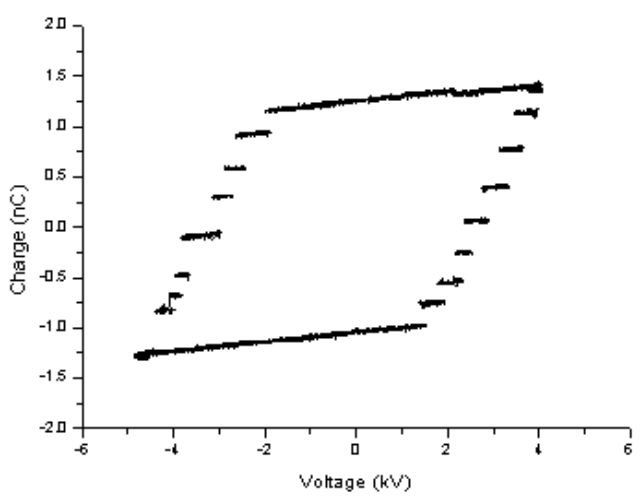

(b)

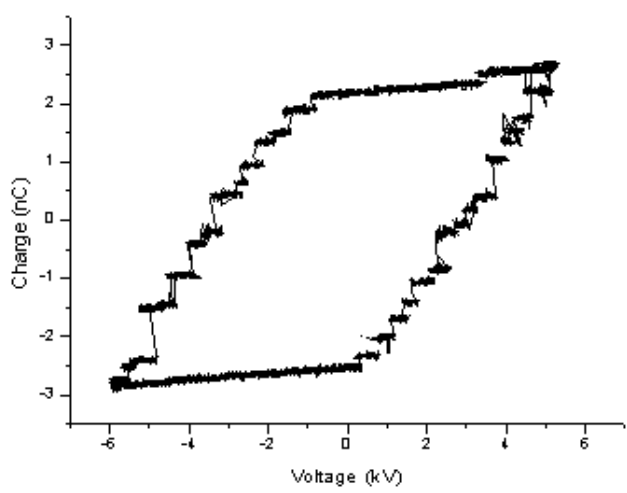

(d)

Figure 10. Voltage-charge Lissajous figure for fine steel wire mesh (\#325, $0.035 \mathrm{~mm}$ ) at (a) $2.8 \mathrm{kV}$, (b) $3.2 \mathrm{kV}$, (c) $3.6 \mathrm{kV}$, (d) $4.0 \mathrm{kV}$. Gap distance $\mathrm{d}=3 \mathrm{~mm}$, gas flow rate $\mathrm{fr}=1 \mathrm{l} / \mathrm{min}$, pressure $\mathrm{p}=1 \mathrm{bar}$ 


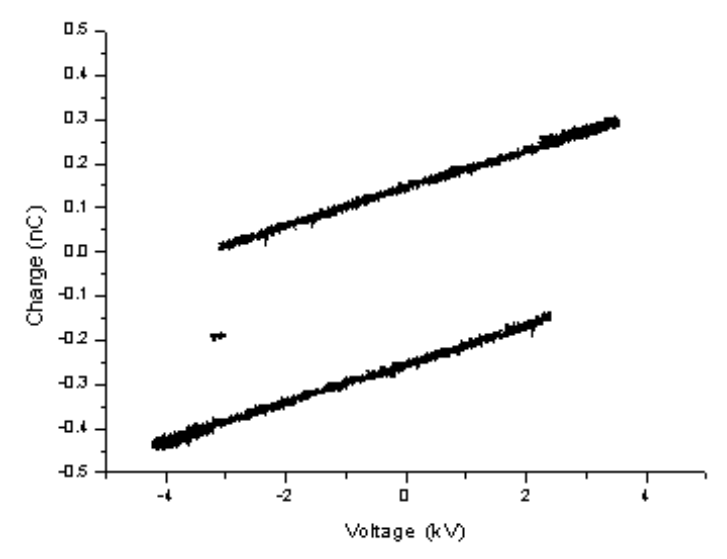

(a)

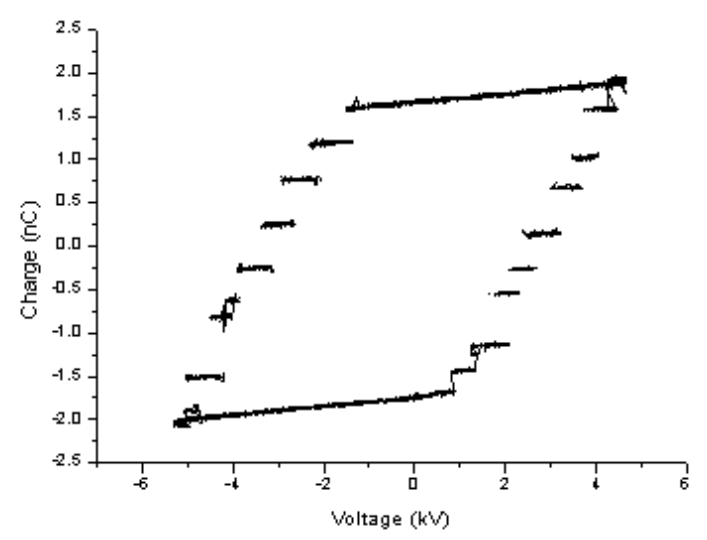

(c)

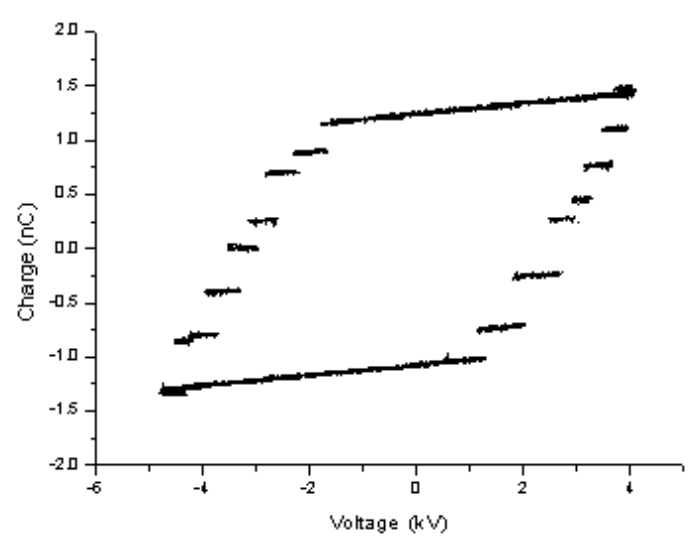

(b)

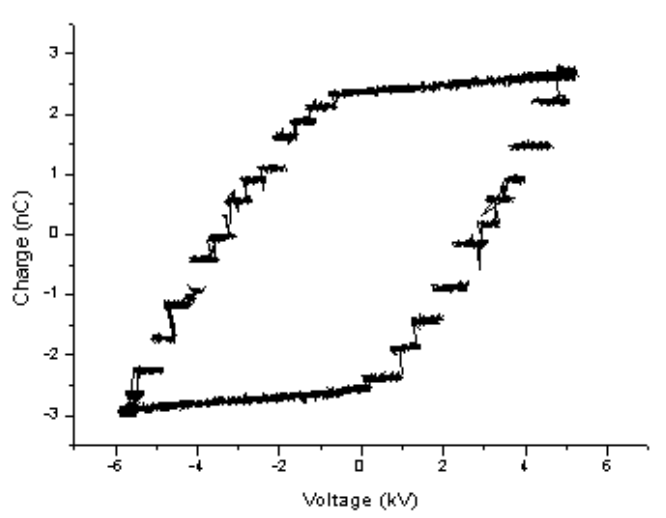

(d)

Figure 11. Voltage-chage Lissajous figure for perforated aluminium (1.2 mm diameter, $23 \%$ open area) at (a) 2.8 $\mathrm{kV}$, (b) $3.2 \mathrm{kV}$, (c) $3.6 \mathrm{kV}$, (d) $4.0 \mathrm{kV}$. Gap distance $\mathrm{d}=3 \mathrm{~mm}$, gas flow rate fr $=1 \mathrm{l} / \mathrm{min}$, pressure $\mathrm{p}=1 \mathrm{bar}$.

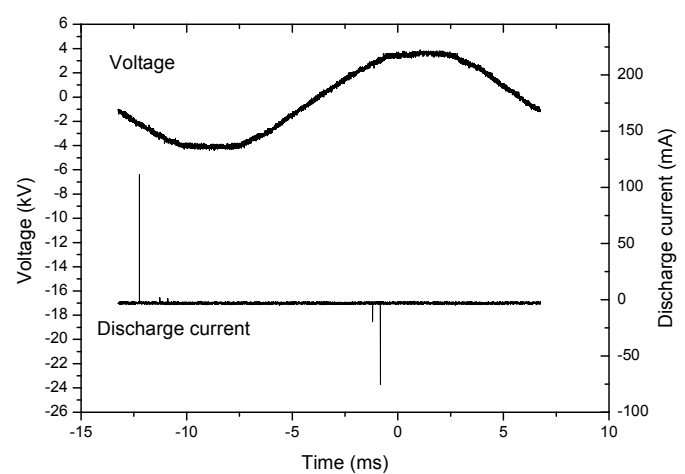

(a)

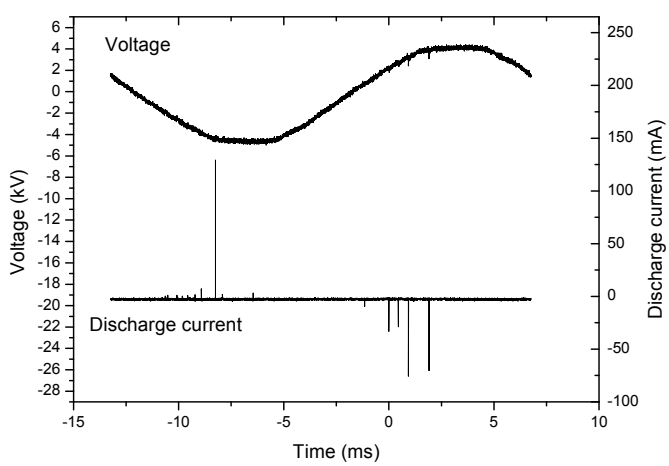

(b) 


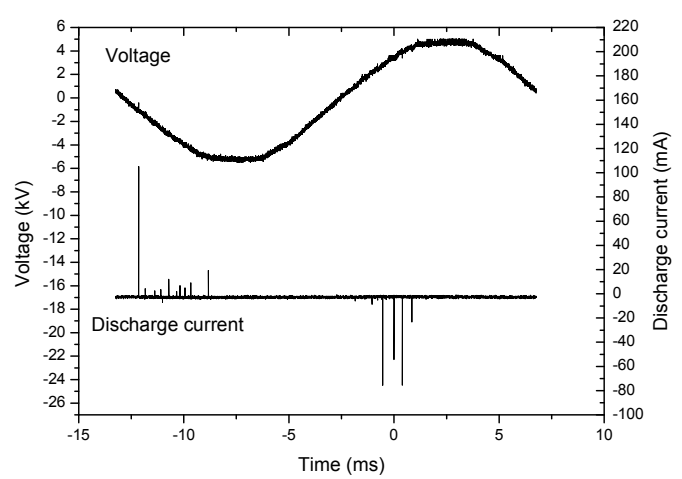

(c)

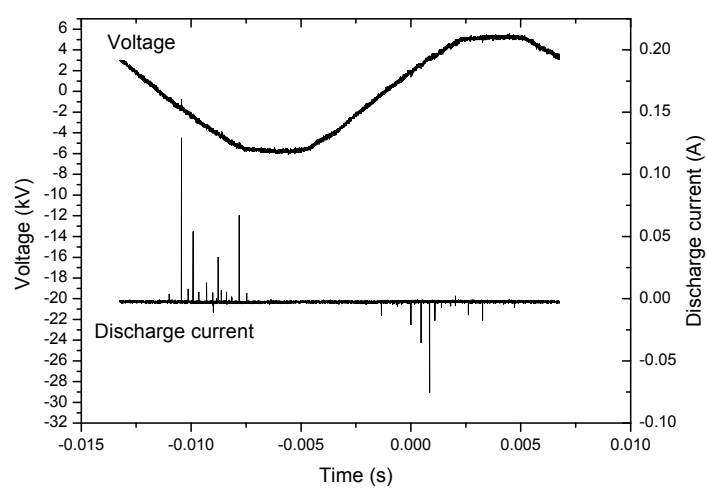

(d)

Figure 12. Voltage and discharge current waveform for steel wire mesh (\#325, $0.035 \mathrm{~mm}$ ) at (a) $2.8 \mathrm{kV}$, (b), 3.2 $\mathrm{kV}$, (c) $3.6 \mathrm{kV}$, (d) $4.0 \mathrm{kV}$. Gap distance $\mathrm{d}=3 \mathrm{~mm}$, gas flow rate $\mathrm{fr}=1 \mathrm{l} / \mathrm{min}$, pressure $\mathrm{p}=1 \mathrm{bar}$

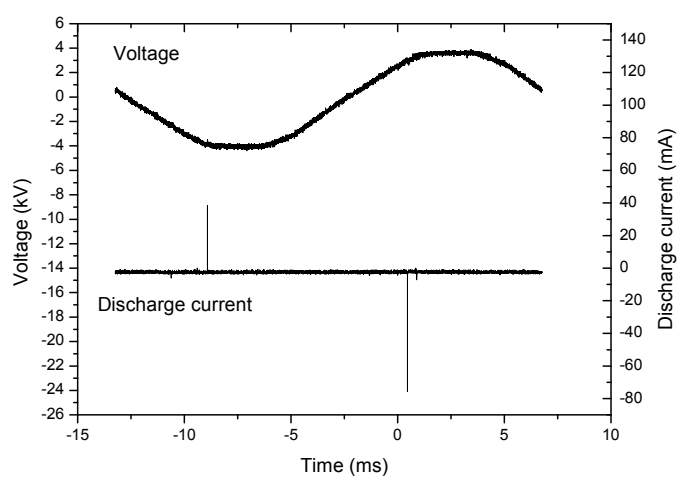

a)

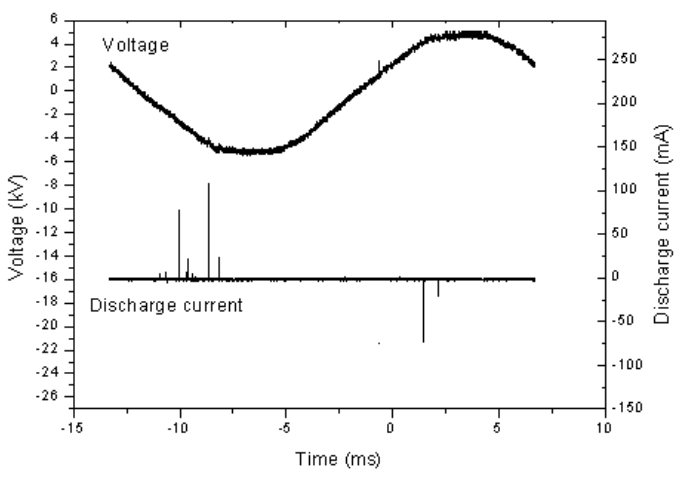

c)

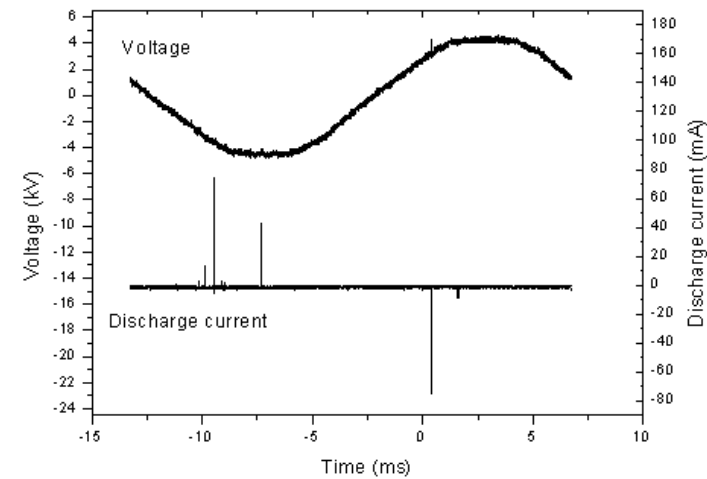

b)

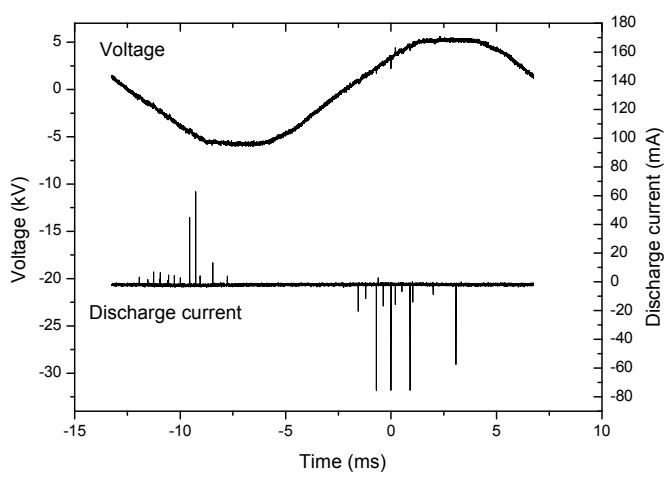

d)

Figure 13. Voltage and discharge current waveform for perforated aluminium (1.2 $\mathrm{mm}$ diameter, $23 \%$ open area) at (a) $2.8 \mathrm{kV}$, (b), $3.2 \mathrm{kV}$, (c) $3.6 \mathrm{kV}$, (d) $4.0 \mathrm{kV}$. Gap distance $\mathrm{d}=3 \mathrm{~mm}$, gas flow rate fr $=1 \mathrm{l} / \mathrm{min}$, pressure $\mathrm{p}=$ 1 bar. 